\title{
Mechanical behavior of a lower limb prosthetic socket made of natural fiber reinforced composite
}

\author{
Wahbi Mankai***, Sami Ben Brahim**, Brahim Ben Smida****, Ridha Ben Cheikh** and Moez Chafra**** \\ *Al Ahsa College of Technology, Technical and Vocational Training Corporation, Saudi Arabia \\ **Laboratory of Materials, Optimization and Energy for Sustainability, National Engineering School of Tunis, University of Tunis, El Manar, BP \\ 37, Le Belvedere 1002 Tunis, Tunisia \\ ***Laboratory of Civil Engineering, National Engineering School of Tunis, University of Tunis, El Manar, BP 37, Le Belvedere 1002 Tunis, Tunisia \\ ****Applied Mechanics and Systems Research Laboratory, Tunisia Polytechnic School, University of Carthage, BP 743, La Marsa 2078, Tunisia \\ *Corresponding Author: wahbi.mankai@enit.utm.tn
}

Submitted: $26 / 09 / 2019$

Revised: $\quad 03 / 05 / 2020$

Accepted: 19/05/2020

\begin{abstract}
Transtibial sockets are commonly made of composites reinforced with expensive synthetic fibers such as carbon or glass fibers. It would be very beneficial to replace conventional fibers with the natural ones produced locally using an abundant wild plant like alfa (Stipa tenacissima) fiber that is economically sustainable and environmentally friendly. This work is aimed at studying the static and dynamic behavior of transtibial sockets produced from alfa and carbon fibers.

The ultimate strength obtained during the static test on the carbon fiber socket and the alfa fiber socket is 3,400 and 2,900 N, respectively. Fatigue testing on the alfa fiber socket yielded a fatigue life of about 2,325,000 cycles. Locally produced alfa fibers could be used as reinforcement of composite materials in orthopedic applications such as transtibial sockets. This could make prosthesis more affordable and serve as basis for design of new standard sockets as a result of fatigue and strength data. Further mechanical viability study should be performed to ensure the feasibility of using alfa fibers in sockets.
\end{abstract}

Keywords: Transtibial Socket; Cyclic Test; Fatigue Life; Natural Fiber; ISO 10328 Standard.

\section{INTRODUCTION}

Rehabilitation aims to improve the autonomy of people with motor disabilities (Legro et al., 2001). Orthopedic equipment plays a significant role in providing a certain level of freedom to the disabled and guaranteeing professional and social integration (Legro et al., 2001). Unfortunately, prostheses are still unaffordable for some amputees (Laferrier et al., 2018).

Materials nature and quality used for making prosthesis have a direct effect on its cost, and the choice of low-cost materials can make such prostheses accessible to a larger number of people (Richardson et al., 2008), especially in developing countries. Transtibial prostheses are composed mainly of three components: a foot, a pylon, and a socket made of a composite material reinforced with synthetic fibers such as carbon or glass fibers (Campbell et al., 2012). The high mechanical properties of such fibers make them expensive (Begum et al., 2013), particularly in countries where these synthetic fibers are imported. Therefore, it has become imperative to look for local alternative fibers, which are more cost-effective than those used in conventional sockets, while maintaining the same mechanical performances. Currently, growing international research seeks to integrate natural fibers into composite materials taking advantage of their mechanical performances, light weight, and economic qualities (Furqan et al., 2015; Pickering et al., 2016). 
In addition to their positive economic and environmental outlook (Furqan et al., 2015), natural fibers could have a socioeconomic impact since their mass production could lead to job opportunities in urban and rural areas and contribute to poverty alleviation (Begum et al., 2013; David et al., 2012).

In this study, we are interested in local fibers extracted from alfa plant (Rokbi et al., 2011; Belouadah et al., 2014). The alfa is the common name of the esparto grass or Stipa tenacissima plant. It is a typical Mediterranean grass. It is abundant in Spain and North African countries (Dallel, 2012). Formerly, the use of the alfa plant was limited to the preparation of craft items such as baskets, espadrilles, or fish traps (Fajardo et al., 2015; Selmi et al., 2005). Recently, it has been used in the papermaking industry (Selmi et al., 2005).

Several studies have reported the possibility of using alfa fiber as reinforcement for composite materials. Ben Brahim et al. (2007) explored the possibility of using alfa fiber for reinforcement in composite and reported the effect of fiber orientation and volume fraction on tensile properties of unidirectional alfa-polyester composites. Other works have focused on alfa fiber composites using different matrices and different processes (Maafi et al., 2010; Ben Cheikh et al., 2014). However, the first study on the use of alfa fiber in a biomedical application was presented (Ben Youssef, 2007; Vermeulen et al., 2008), introducing a socket made from poly (methyl methacrylate) (PMMA) matrix reinforced with 25w\% nonwoven alfa fiber (Ben Youssef, 2007). The manufacture of these sockets was justified by the results of tensile tests, which showed specific values for the composite specimens (PMMA-alfa fiber) close to those obtained for the composite specimens (PMMA-glass fiber) (Ben Youssef, 2007). Although this study was carried out at the manufacturing stage of the sockets without going into their mechanical testing, it has incited further research in this area. Recently, Ghali et al. (2014) prepared alfa fiber nonwoven fabrics blended with various fibers and characterized by different mechanical and physical properties. However, the mechanical testing of sockets reinforced by nonwoven alfa fiber is still not mentioned in the literature.

There is no specific standard for testing sockets (Campbell et al., 2012; Current et al., 1999; Gerschutz et al., 2012). Most works relating to mechanical tests on sockets refer to the ISO 10328 standard (ISO 10328:1996). In the technical note (Neo et al., 2000), a detailed description of the method used to prepare specimens is presented. One of the methods used to transmit test loads to the prosthetic assemblies via the socket is the application of a mandrel that is embedded in plaster at the proximal section of the socket (Neo et al., 2000). Results from dynamic testing for fatigue failure on a complete prosthesis have been presented by Wevers et al. (1987). Winson et al. (2006) performed cyclic testing on two transtibial flexible-shank monolimbs to show the changes in their structural behavior. Chiad et al. (2017) compared the stress endurance of two materials used for the manufacture of above-knee prosthetic socket. This approach was not based on ISO 10328. The authors' tests were performed on flat samples, and the results were presented as S-N fatigue curve, which describes the relation between cyclic stress amplitude and number of cycles to failure (Gope, 2012). While one can find results concerning static tests on sockets described by adequate data (Current et al., 1999; Gerschutz et al., 2012), it is rare to find fatigue curves describing cyclic tests. The importance of data curves in cyclic tests cannot be overlooked because it is needed to determine the fatigue life of the tested product.

The plaster commonly used in the test device (Neo et al., 2000) as a support for the socket can be replaced by an elastic material for ease and evenly distribution of the mechanical load (Jia et al., 2004; Portnoy et al., 2008).

The main goal of the current study is to perform static and cyclic tests according to the ISO 10328 standard on sockets made of nonwoven alfa fiber in order to characterize their mechanical performance. A cyclic test was carried out on a socket made of nonwoven alfa fiber. The resulting data is presented in the form of curves that are used to determine the fatigue life of the socket.

\section{METHODS}

\section{A) Sample preparation}

The socket samples were built in a laboratory specialized in the manufacture of orthopedic equipment. In all, three sockets were prepared: two sockets reinforced with nonwoven alfa fiber and one reinforced with carbon fiber. The 
matrix used for both types of socket was based on PMMA. The mixture of resin is prepared by adding a hardener to the prepolymer at room temperature in a percentage ratio of 85:15.

The manufacture of the sockets begins with the preparation of a plaster mold. To save time and to have identical plaster molds, a negative mold was prepared in two parts that will be also used for molding the artificial stump (Fig. 1 and Fig. 2).

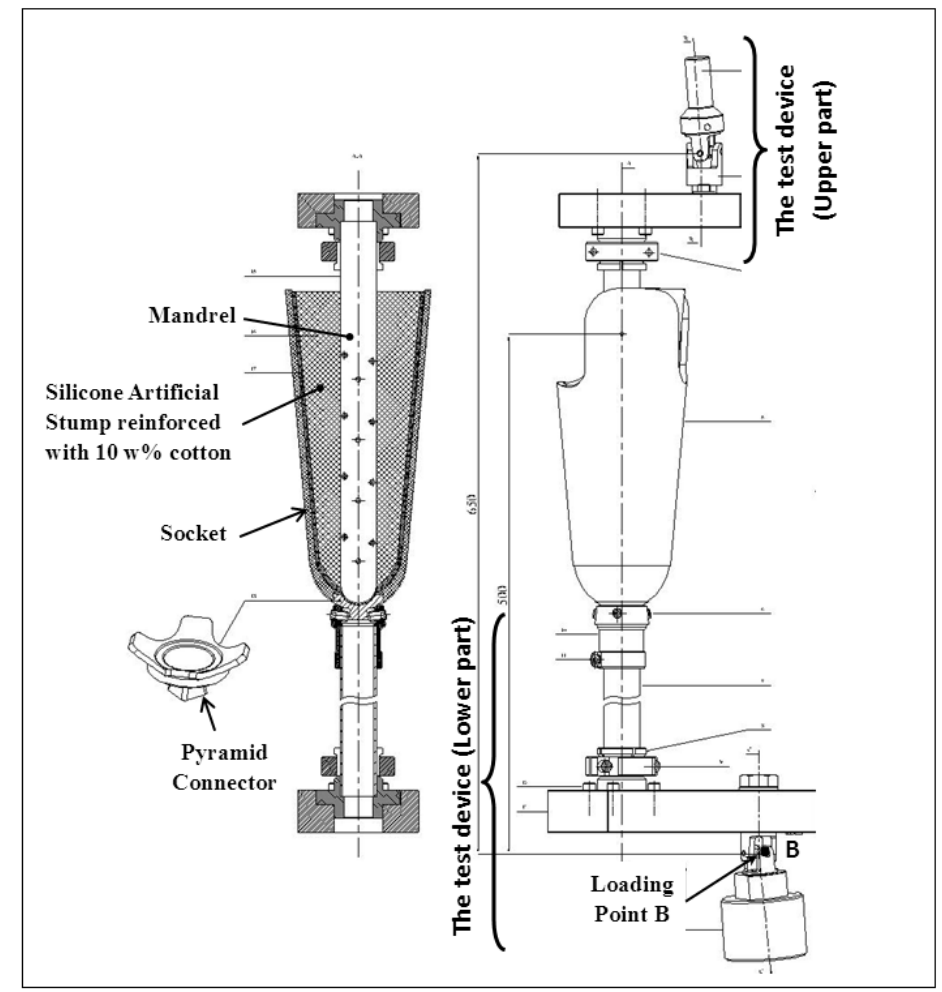

Figure 1. Socket, artificial stump, and testing device assembly (SATA).

The sockets were obtained by a resin transfer molding process (Campbell et al., 2012). The composite used in the sockets is considered as a sandwich structure. Indeed, the reinforcement is formed by four layers of perlon and one layer of carbon fiber mat or nonwoven alfa fiber (Chiad et al., 2017). It should be noted that the layer of carbon fiber mat (or nonwoven alfa) is doubled only at the level of the pyramid connector (Fig. 1).

\section{B) Preparation of the silicone stump reinforced with cotton}

Various methods have been used to attach the socket to the test device support (Campbell et al., 2012; Current et al., 1999; Neo et al., 2000; Wevers et al., 1987). An artificial stump (Fig. 1) of domestic silicone reinforced with 10w\% cotton fiber was made in order to simulate the transfer and the distribution of the loads on the socket (Jia et al., 2004; Portnoy et al., 2008). The used silicone is a monocomponent of the acetic type, which polymerizes spontaneously in contact with air into elastic rubber. The preparation of the artificial stump is a delicate and accurate procedure. It is the basis of the alignment step of Socket, Artificial stump, and Test device Assembly (SATA) (Fig. 1). The method followed for the alignment of the SATA is the same as that presented in the report of Neo et al. (2000). The various steps for molding the artificial stump and the preparation of the cotton-reinforced silicone composite are presented in Fig. 2. 


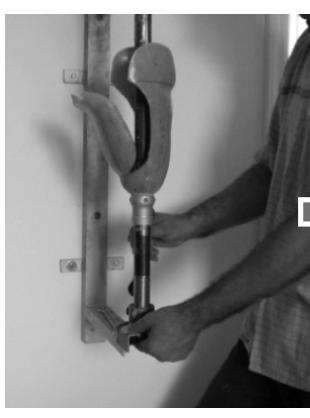

(a) Alignment of the negative two parts mold

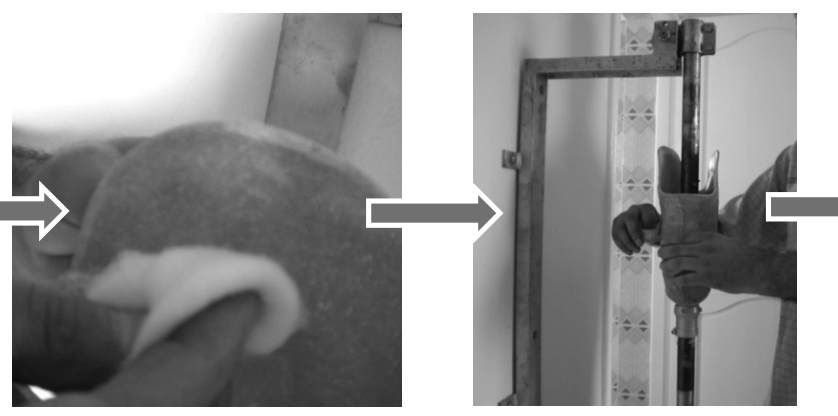

(b) Wipe the inside of the mold with Vaseline to facilitate demolding (c) Closing the mold with tape

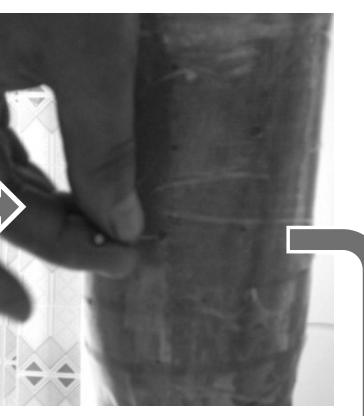

(d) Opening of vents to release air trapped during molding

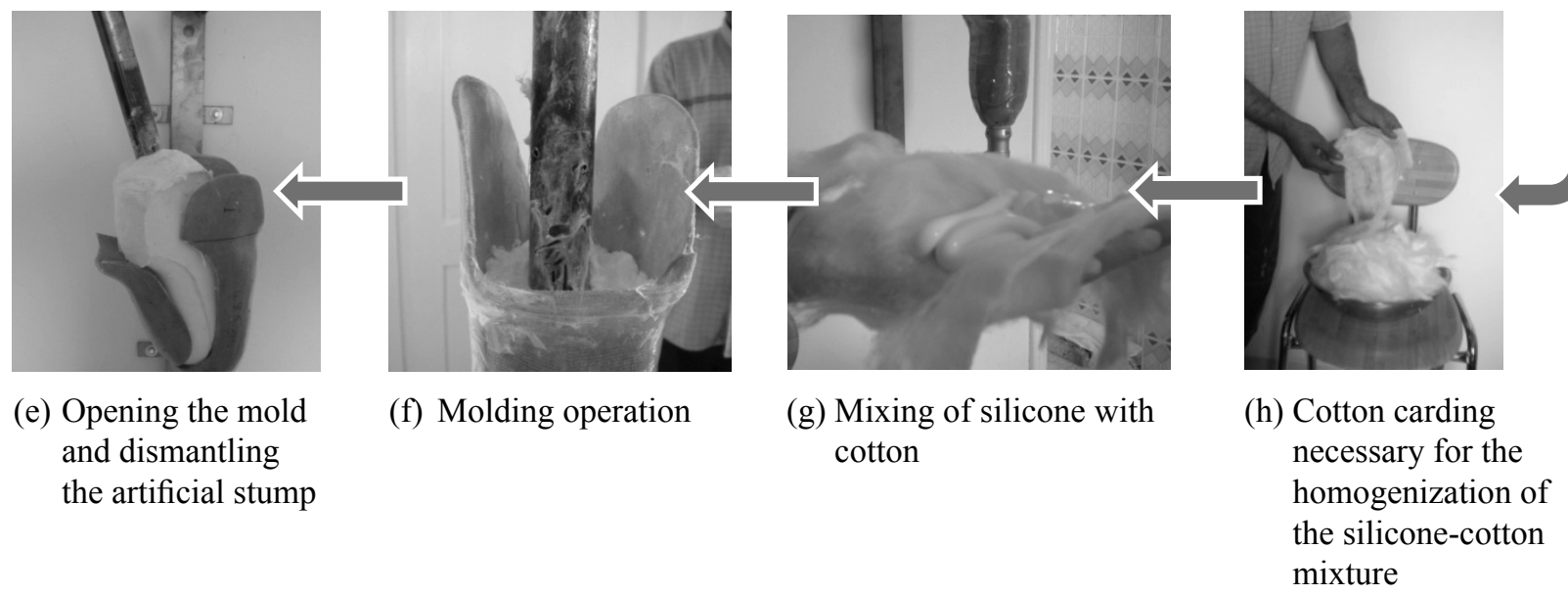

Figure 2. The main steps for the preparation of the artificial stump.

\section{C) Mechanical testing of the sockets}

Three trials were conducted; the first one is a static test on a socket reinforced with carbon fibers. The second one is a static test on a socket reinforced with nonwoven alfa fibers. And the third one is a cyclic test on a socket reinforced with nonwoven alfa fibers.

The tests were carried out in the laboratory of mechanical tests of the research company Tecnotessile, Italy. The test machine used is a brand fatigue machine, Italsigma MTS 407 Controller, with maximum capacities (100 kN, 25 $\mathrm{Hz}$ ). The tests were conducted at ambient temperatures ranging between $20^{\circ} \mathrm{C}$ and $25^{\circ} \mathrm{C}$.

In order to compare the static test results of this study with those of previous works (Campbell et al., 2012; Current et al., 1999; Gerschutz et al., 2012), the test device was designed with the offset values of the loading condition II, and all tests were performed at test load level A100, in accordance with ISO 10328.

The two static tests were run by incrementing the force at a rate of $200 \mathrm{~N} / \mathrm{s}$, until sample failure. The force that the test specimen must withstand in accordance with the requirements of ISO 10328 standard depends on the type of failure that is most likely to occur. In condition II at level load A100, this force is prescribed at 4,025 $\mathrm{N}$ for the brittle mode and prescribed at 3,019 $\mathrm{N}$ for the ductile mode.

For the cyclic test, the socket was prepared from a PMMA-based resin reinforced with nonwoven alfa fiber. It was then mounted and aligned with the testing equipment in accordance with ISO 10328. The SATA was fastened by the grips of the hydraulic fatigue testing machine. The upper grip, which is instrumented with a force transducer, is 
unmovable, while the lower grip, which is attached to hydraulic piston, is movable and transmits the excitation force $\boldsymbol{F}(\boldsymbol{t})$ prescribed by ISO 10328 and given by

$$
F(t)=F_{m}+\frac{F_{c}}{2} \cdot \sin (\omega t)
$$

where $\boldsymbol{F}_{\boldsymbol{m}}$ is the average strength, $\boldsymbol{F}_{\boldsymbol{c}}$ is the strength variation extent, and $\boldsymbol{\omega}$ is the angular frequency.

The cyclic test consists in measuring the deflection of the lower grip (represented by loading point B shown in Fig. 1) as a function of the number of loading cycles. During the fatigue test, point B follows an oscillatory movement.

\section{RESULTS}

\section{A) Static tests}

In the static test, the socket was loaded until a failure occurs, and the maximum strength attained was compared to the force recommended by the ISO 10328 standard. Two static tests were performed; the first one on a socket reinforced with carbon fibers and the second one on a socket reinforced with alfa fibers. According to the experimental finding of Fig. 3, it can be confirmed that the mode of failure is ductile for both sockets, because their test curves were accompanied by significant plastic deformation (Gope, 2012). The maximum strength reached for carbon fibers socket was approximately $3,400 \mathrm{~N}$, which corresponds to $113 \%$ of the target, while the maximum strength reached for the alfa fibers socket was about 2,900 N, which corresponds to $96 \%$ of the target (Fig. 3).

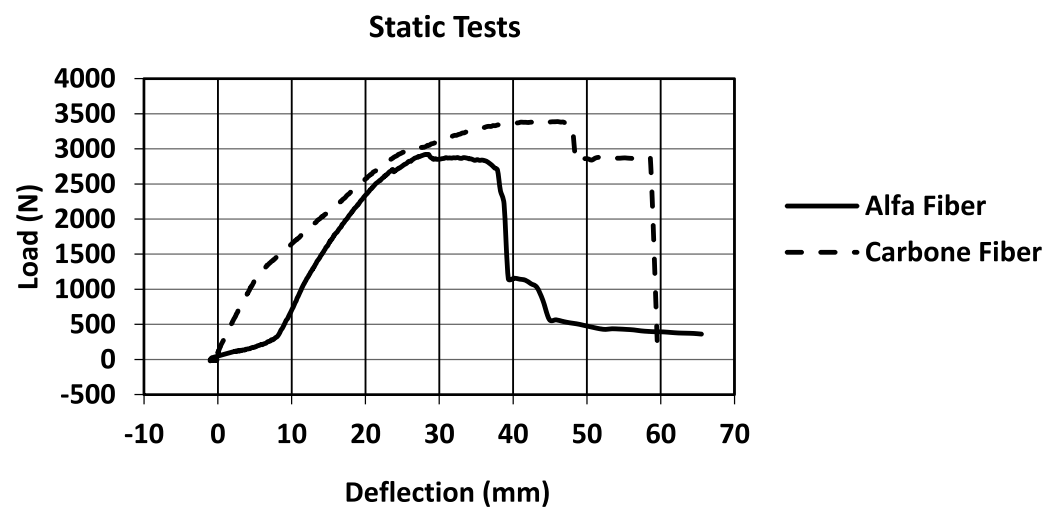

Figure 3. Loading to failure of carbon fiber socket and alfa fiber socket.

For both, the socket reinforced with carbon fiber and the socket reinforced with nonwoven alfa fiber, the failure occurred at the bottom of the socket at the level of the pyramid connector (Fig. 1), as shown in Fig. 4.

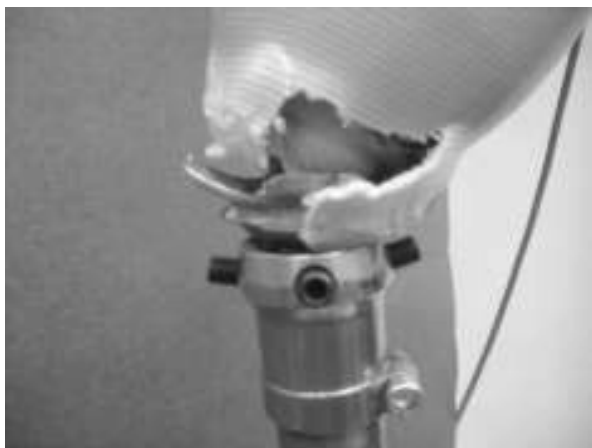

(a)

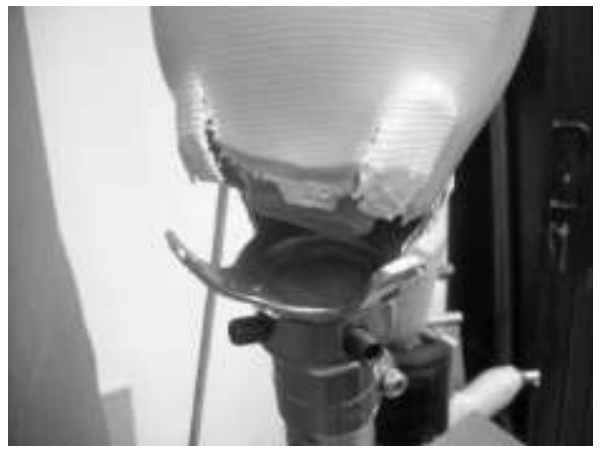

(b)

Figure 4. (a) Break of the carbon fiber socket. (b) Break of the alfa fiber socket. 


\section{B) Cyclic test on nonwoven alfa fiber socket}

The fatigue test was performed on a socket reinforced with nonwoven alfa fiber. The results of this test are presented in Fig. 5(a) in the form of two curves (Linf and Lsup). These two curves enclose the oscillations of the lower loading point B (Fig. 1). They have the same shape, which is composed of three distinct zones. The first zone is characterized by a steep that rises to 70,000 cycles. The second zone is characterized by a low slope nearly linear over 2,000,000 cycles. The third zone is characterized by a steep slope that is likely to end up with sample failure. The shape of these curves is indicative of that of a creep curve. We note that, at $\mathrm{t}=0$, the deflection is about $15 \mathrm{~mm}$, and the amplitude of the deflection is equal to $2.3 \mathrm{~mm}$. In Fig 5(a), a third curve, which is drawn by a dashed line, represents the extent of variation of the oscillations, which corresponds to twice the amplitude of the oscillations. It is noticed that the amplitude is constant over most of this curve; then, at about 2,300,000 cycles, it starts to grow rapidly, indicating the degradation of the mechanical properties of the socket.

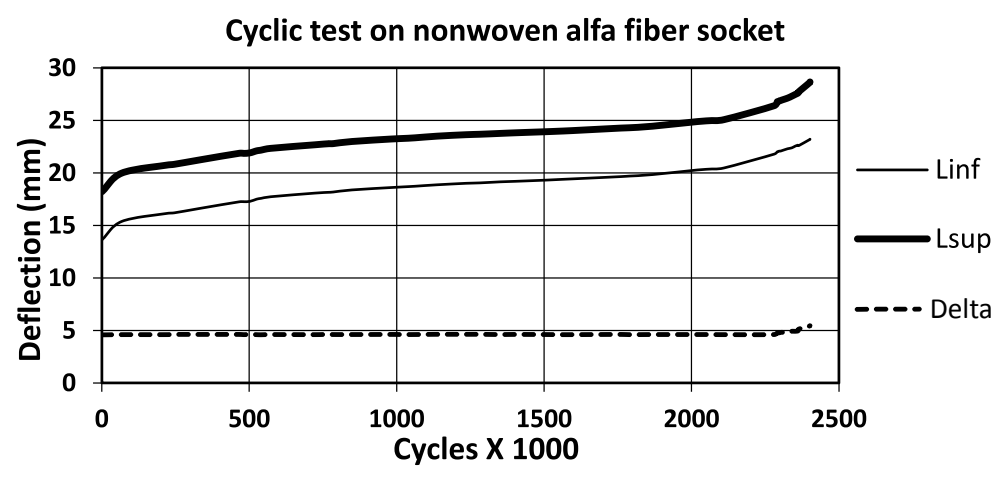

(a)

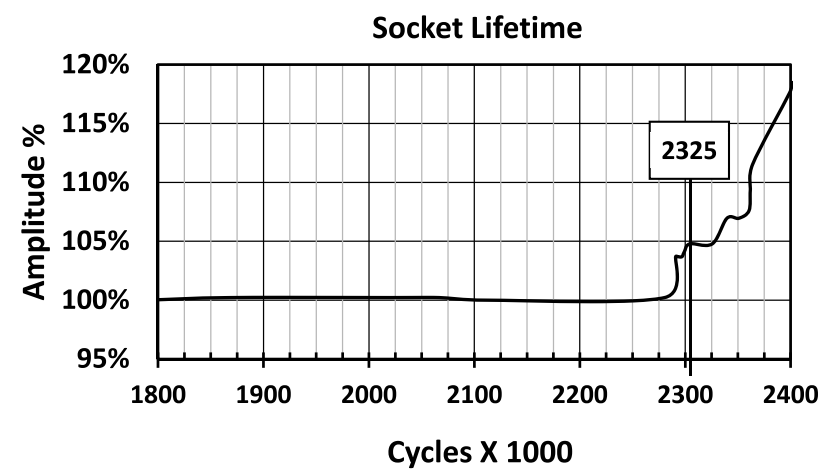

(b)

Figure 5. (a) Fatigue curves of the alfa fiber socket, where Linf is the minimal deflection, Lsup is the maximum deflection, and Delta is the deflection extend.

(b) Determination of the lifetime of the alfa fiber socket.

In order to determine the lifetime of the socket, the fluctuation of the third curve was analyzed. The fatigue life of the socket in terms of number of cycles was chosen at the point when the range of oscillations exceeds $5 \%$ of its mean value as determined from the plateau region of the third curve as shown in Fig. 5(a). This criterion was inspired from the French standard (NF T 51-120-1: 1995). The final phase of the third curve shown in Fig. 5(a) is presented as a percentage in Fig. 5(b). The fatigue life of the socket is about 2,325,000 cycles. Hence, dividing this number by 3,000,000 cycles, the endurance required by the ISO 10328 standard, the sample lifetime obtained is $77.5 \%$ of the target. 


\section{DISCUSSION}

\section{A) Static tests}

The result of the static test for both types of sockets (reinforced with a carbon fiber or a nonwoven alfa fiber) proved that the most stressed section is at the bottom of the socket at the level of the pyramid connector, as presented in Fig. 4. This result has been already found in previous works (Campbell et al., 2012; Current et al., 1999; Gerschutz et al., 2012). The socket made of carbon fibers is more efficient than its counterpart made from alfa fiber since their ultimate strengths are, respectively, $3400 \mathrm{~N}$ and $2900 \mathrm{~N}$. The value of the ultimate strength of the socket reinforced with a mat of carbon fibers is very close to the value found long ago (Current et al., 1999), for a socket made from an acrylic resin reinforced with unidirectional carbon fibers as shown in Table 1.

Table 1. Ultimate strengths obtained for static tests of this study and the previous work (Current et al., 1999).

\begin{tabular}{llrr}
\hline The tests conditions & Concerned study & Reinforcement fiber & Ultimate strength (N) \\
\hline \hline & This study & Mat carbon fiber & 3400 \\
\cline { 2 - 4 } & & Nonwoven alfa fiber & 2900 \\
\cline { 2 - 4 } $\begin{array}{l}\text { All tests are } \\
\text { performed at A100 } \\
\text { loads in condition II. }\end{array}$ & $\begin{array}{l}\text { Previous work (fig. 2 } \\
\text { of Current } \text { et al., 1999) }\end{array}$ & Unidirectional carbon & 3160 \\
\cline { 3 - 4 } & & Carbon fiberglass stockinet & 3073 \\
\cline { 3 - 4 } & & fiberglass stockinet & 2409 \\
\cline { 3 - 4 } & & Carbon cloth & 2218 \\
\hline
\end{tabular}

By comparing the ultimate strength reached during the static test on the alfa fiber socket with the results obtained by Current et al., (1999) and summarized in Table 1, it can be observed that alfa fibers present a midrange performance compared to other materials.

\section{B) Fatigue test}

The experimental results show a sinusoidal curve carried by a curve very close to a creep curve. The shape resemblance between the creep curves and the curves obtained from the fatigue test can be explained by the presence of a constant component $\left(\mathbf{F}_{\mathbf{m}}\right)$ of equation (1). According to the principal of superposition of forces, the response obtained in the cyclic test is the sum of a response to the static loading and a response to the dynamic loading as indicated by equation (1). Generally, creep tests demonstrate the viscoelastic behavior of the materials, in particular composite materials whose damage mechanisms are more complex than the conventional materials (Kaminski et al., 2015; Jollivet et al., 2013). Thus, the fatigue curves of Fig. 5(a) reveal the fatigue behavior (Malpot et al., 2015) of the tested socket composite material obtained from acrylic matrix reinforced with nonwoven alfa fibers.

According to fig. 5(b), the onset of failure seems to occur shortly before 2,325,000 cycles, where there is a sudden leaping on the curve of Fig. 5(b). It could be said that the chosen criterion, based on the oscillation amplitude and inspired from the French standard (NF T 51-120-1: 1995), is optimistic. Other more sensitive criteria may be used such as that of the thermographic method (Fargione et al., 2002). Whatever the method used to determine the socket lifetime, the fatigue curves are of great importance since they are used to compare fatigue test results of sockets made from different materials and could help in defining a specific standard for testing sockets.

\section{CONCLUSION}

The results obtained from static tests show that alfa fibers are a promising alternative material for use in sockets. The result of fatigue test reveals the viscoelastic behavior of the composite material reinforced with nonwoven alfa 
fibers and provides a socket lifetime of about $2,325,000$ cycles that represent $77.5 \%$ of the target required by the ISO 10328 standard.

The results of this study could be a first step towards defining a specific standard for testing sockets, particularly fatigue testing. Further tests such as compression test and economic viability test should be conducted to determine the cost of prosthesis made with a socket reinforced with nonwoven alfa fibers as compared to other fibers.

\section{REFERENCES}

Begum, K. \& Islam, M.A. 2013. Natural Fiber as a substitute to Synthetic Fiber in Polymer Composites: A Review. Research Journal of Engineering Sciences, 2(3): 46-53.

Belouadah, Z., Ati, A., Rokbi, M., Bezazi, A. \& Imad, A. 2014. Optimisation Des méthodes D'extraction Et Caractérisation Mécanique De La Fibre Alfa En Vue De Son Application Comme Renfort Des Matériaux Composites. Journal of Materials, Processes and Environment, 2(1): 51-57.

Ben Brahim, S. \& Ben Cheikh, R. 2007. Influence of fiber orientation and volume fraction on the tensile properties of unidirectional Alfa-polyester composite. Composites Science and Technology, 67(1): 140-147.

Ben Cheikh, R., Aaron, M. \& Bellington, S. 2014. Mechanical Characterization and Modeling of Poly( $\beta$-hydroxybutyrate)-copoly( $\beta$-hydroxyvalerate)-Alfa Fiber- Reinforced Composites. Polymer Composites, 35(9): 1758-1766.

Ben Youssef, Y. 2007. Composite à base de non-tissé d'Alfa et matrice biodégradable. M. Res, National School of Arts and Textile Industries, France.

Campbell, A.I., Sexton, S., Schaschke, C.J., Kinsman, H., McLaughlin, B. \& Boyle, M. 2012. Prosthetic limb sockets from plant-based composite materials. Prosthetics and Orthotics International, 36(2): 181-189.

Chiad, J.S. \& Tahir, M.S. 2017. Enhancement of the mechanical properties for above-knee prosthetic socket by using the bamboo fiber. International Journal of Energy and Environment: Issue on Applied Mechanics Research, 8(4): 131-138.

Current, T.A., Kogler, G.F. \& Barth, D.G. 1999. Static structural testing of trans-tibial composite sockets. Prosthetics and Orthotics International, 23(2): 113-122.

Dallel, M. 2012. Evaluation du potentiel textile des fibres d'Alfa (Stipa Tenacissima L.) : Caractérisation physico-chimique de la fibre au fil. PhD. Thesis, University of Haute Alsace - Mulhouse, France.

David, B.D. \& GangaRao, H. 2012. Review: Critical review of recent publications on use of natural composites in infrastructure. Composites, Part A: Applied Science and Manufacturing, 43(8): 1419-1429.

Fajardo, J., Verde, A., Rivera, D., Obón, C. \& Leopold, S. 2015. Traditional Craft Techniques of Esparto Grass (Stipa tenacissima L.) in Spain. Economic Botany, $\mathbf{X X}(\mathrm{X}):$ 1-7.

Fargione, G., Geraci, A., La Rosa, G. \& Risitano, A. 2002. Rapid determination of the fatigue curve by the thermographic method. International Journal of Fatigue, 24(1): 11-19.

Furqan, A., Heung, S.C. \& Myung, K.P. 2015. A Review: Natural Fiber composites Selection in View of Mechanical, Light Weight, and Economic Properties. Macromolecular Materials and Engineering, 300: 10-24.

Gerschutz, M.J., Haynes, M.L., Nixon, D. \& Colvin, J.M. Strength evaluation of prosthetic check sockets, copolymer sockets, and definitive laminated sockets. Journal of Rehabilitation Research and Development, 49(3): 405-426.

Ghali, L., Halimi, M.T, Ben Hassen, M. \& Sakli, F. 2014. Effect of Blending Ratio of Fibers on the Properties of Nonwoven Fabrics Based of Alfa Fibers. Advances in Materials Physics and Chemistry, 4: 116-125.

Gope, P.C. 2012. MACHINE DESIGN - Fundamentals and Applications. Eastern Economy Edition.

ISO 10328:1996. Prosthetics. Structural testing of lower-limb prostheses.

Jia, X., Zhang, M. \& Lee, W.C.C. 2004. Load transfer mechanics between trans-tibial prosthetic socket and residual limb-dynamic effects. Journal of Biomechanics, 37(9): 1371-1377.

Jollivet, T., Peyrac, C. \& Lefebvre, F. 2013. Damage of composite materials. Procedia Engineering, 66: 746-758. 
Kaminski, M., Laurin, F., Maire, J.F., Rakotoarisoa, C. \& Hémon, E. 2015. Fatigue Damage Modeling of Composite Structures: the ONERA Viewpoint. Aerospace Lab, 9: 1-12.

Laferrier, J.Z., Groff, A., Hale, S. \& Sprunger, N.A. 2018. A Review of Commonly Used Prosthetic Feet for Developing Countries: A Call for Research and Development. Journal of Novel Physiotherapies, 8: 380: 1-10

Legro, M.W., Reiber, G.E., Czerniecki, J.M. \& Sangeorzan, B.J. 2001. Recreational activities of lower-limb amputees with prostheses. The Journal of Rehabilitation Research and Development, 38(3): 319-325.

Maafi, E.M., Malek, F., Tighzert, L. \& Dony, P. 2010. Synthesis of Polyurethane and Characterization of its Composites Based on Alfa Cellulose Fibers. Journal of Polymers and the Environment, 18(4): 638-646.

Malpot, A., Touchard, F. \& Bergamob, S. 2015. Fatigue behavior of a thermoplastic composite reinforced with woven glass fibers for automotive application. Procedia Engineering, 133: 136-147.

Neo, L.D., Lee, P.V.S. \& Goh, J.C.H. 2000. Technical note: Principal structural testing of trans-tibial prosthetic assemblies: specimen preparation. Prosthetics and Orthotics International, 24(3): 241-245.

NF T 51-120-1: 1995. Plastics and composites- Determination of the bending fatigue properties- Part 1: General principles.

Pickering, K.L., Aruan Efendy, M.G. \& Le, T.M. 2016. A review of recent developments in natural fiber composites and their mechanical performance (Review). Composites: Part A, 83: 98-112.

Portnoy, S., Yizhar, Z., Shabshin, N., Itzchak, Y., Kristal,A., Dotan-Marom, Y., Siev-Ner, I. \& Gefen, A. 2008. Internal mechanical conditions in the soft tissues of a residual limb of a trans-tibial amputee. Journal of Biomechanics 41(9): 1897-1909.

Richardson, V. \& Vozzola, E. 2008. Analysis of a Lower Limb Prosthesis. Degree of B.S., Worcester Polytechnic Institute, US.

Rokbi, M., Osmani, H., Imad, A. \& Benseddiq, N. 2011. Effect of Chemical treatment on Flexure Properties of Natural Fiberreinforced Polyester Composite. Procedia Engineering, 10: 2092-2097.

Selmi, S., Aloui, T. \& Helali, M.A. 2005. L'alfa industriel dans la région du centre-ouest de la Tunisie : pilier principal d'allègement de la pauvreté en milieu rural. NEW MEDIT, 4(3): 52-56.

Vermeulen, B., Ben Youssif, Y., Perwuelz, A., Legrand, X., Vroman, P. \& Ben Cheikh, R. 2008. Réalisation d'un composite à base de fibres d'alfa. Revue des Composites et Matériaux Avancés, 18(2): 139-144.

Wevers, H.W. \& Durance, J.P. 1987. Dynamic testing of below-knee prosthesis: assembly and components. Prosthetics and Orthotics International, 11(3): 117-123.

Winson, C.C.L. \& Zhang, M. 2006. Fatigue test of low-cost flexible-shank monolimb trans-tibial prosthesis. Prosthetics and Orthotics International, 30(3):305-315. 